\title{
Marine algae are 'taught' the basics of angular momentum
}

\author{
John Taylor Allen ${ }^{1,2}$ (D) \\ Received: 30 October 2016 / Accepted: 18 August 2017 /Published online: 13 September 2017 \\ (C) The Author(s) 2017. This article is an open access publication
}

\begin{abstract}
Advanced modelling studies and high-resolution observations have shown that flows related to instability of the mesoscale $(\sim 1-10 \mathrm{~km}$ scale) may provide both the fertilisation mechanism for nutrient-depleted (oligotrophic) surface waters and a subduction mechanism for the rapid export of phytoplankton biomass to the deep ocean. Here, a detailed multidisciplinary analysis of the data from an example high-resolution observational campaign is presented. The data provide direct observations of the transport of phytoplankton through baroclinic instability. Furthermore, the data confirm that this transport is constrained by the requirement to conserve angular momentum, expressed in a stratified water column as the conservation of potential vorticity. This constraint is clearly seen to produce long thin filaments of phytoplankton populations strained out along isopycnal vorticity annuli associated with mesoscale frontal instabilities.
\end{abstract}

Keywords Eddies · Potential vorticity · Export production · Instability processes $\cdot$ Ocean fronts $\cdot$ Sub-mesoscale filaments

This article is part of the Topical Collection on the 48th International Liège Colloquium on Ocean Dynamics, Liège, Belgium, 23-27 May 2016

Responsible Editor: Amala Mahadevan

John Taylor Allen

jallen@socib.es; john.allen@port.ac.uk

1 Sistema de Observación y Predicción Costero de las Illes Balears (SOCIB), Palma de Mallorca, Spain

2 School of Earth and Environmental Sciences (SEES), University of Portsmouth, Portsmouth, UK

\section{Introduction}

The Iceland-Færœs Front (IFF) is a perpetual boundary between water masses of Atlantic origin to the south and those of Nordic seas origin to the north (Read and Pollard 1992; Allen et al. 1994; Hallock 1985; Meincke 1978). Using an analytical model of a surface breaking front in a geostrophic current (Killworth et al. 1984), Allen et al. (1994) indicated fastest growing wavelengths of instability around $40-70 \mathrm{~km}$ and that observations of meanders and eddy-like structures at the IFF supported this. Figures in Allen et al. (2005) and later in this paper indicate that this scale for geostrophic instability at the IFF can also be considered characteristic of a 2001 dataset, which is the subject of this manuscript; this is perhaps not surprising at a permanent frontal zone, dominated by mode waters (Read and Pollard 1992; Hallock 1985; Meincke 1978), sampled in the late spring and summer months. By mapping potential vorticity (PV) and its components, a better picture was obtained of instability processes at, and in large part driving, the meandering frontal boundary (Allen and Smeed 1996). The earlier application of the analytical model of Killworth et al. (1984) also predicted that $>85 \%$ of the perturbation energy exchange in the frontal instabilities would be baroclinic; i.e. $<15 \%$ results from horizontal shear. This implied that significant vertical velocities may be observable at the observational scale of these datasets through a quasigeostrophic (QG) 'Omega' equation analysis (Hoskins et al. 1978), and indeed, such subsequent analyses of both datasets (Allen and Smeed 1996; Allen et al. 2005) resulted in diagnosed maps of vertical velocities of several tens of metre per day $\left(\mathrm{m} \mathrm{day}^{-1}\right)$.

More recently, high-resolution modelling studies (Levy et al. 2001; Lapeyre and Klein 2006; Mahadavan 2015) have indicated how three-dimensional flows ( 1-10 km scale) associated with a heavily perturbed unstable front may provide a 

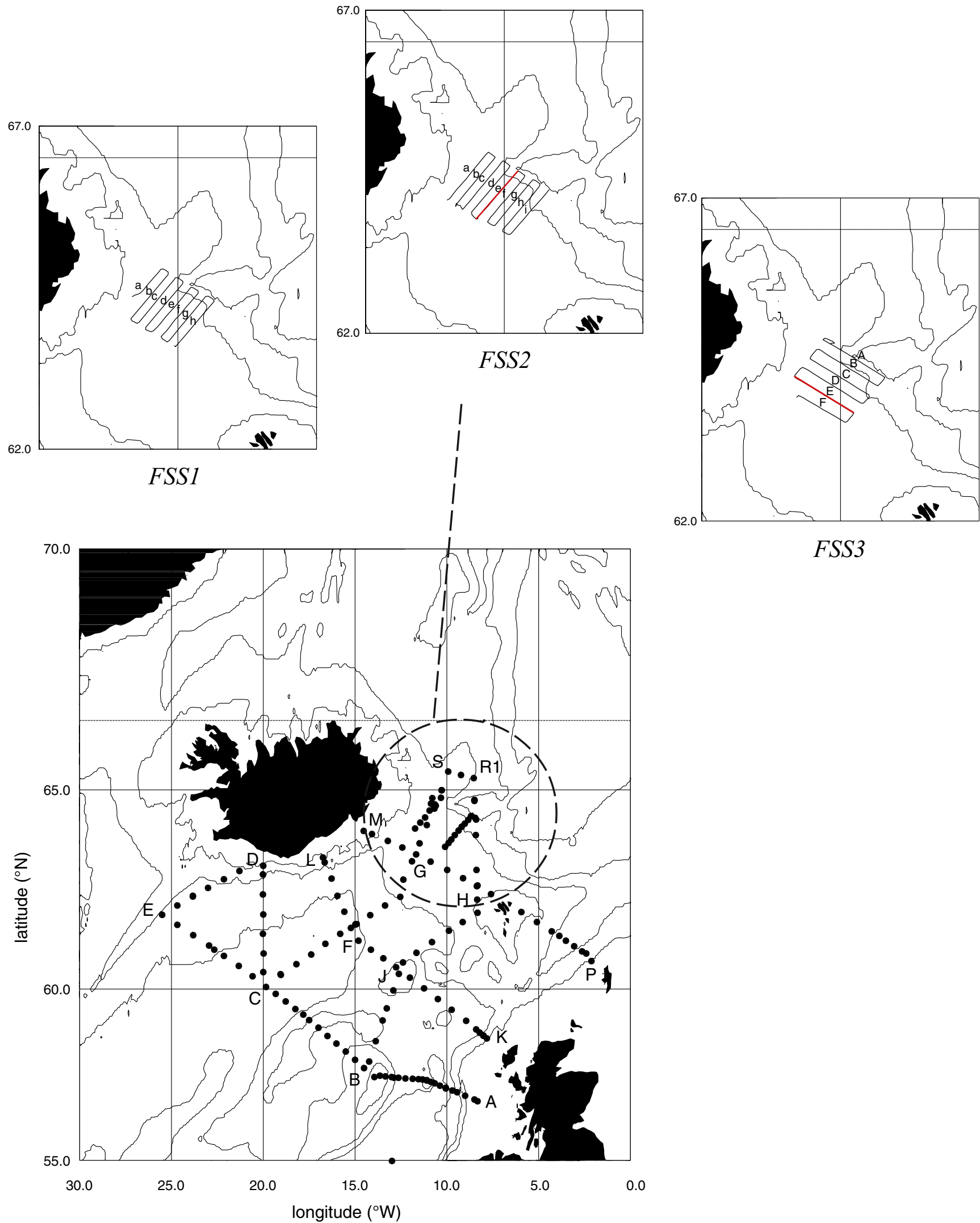

FSS3

Fig. 1 The CTD stations carried out during the first leg of the FISHES cruise (left), setting the context for the three SeaSoar surveys carried out during the second leg (above). Bathymetry contours are $200 \mathrm{~m}, 1000 \mathrm{~m}$,
$2000 \mathrm{~m}, 3000 \mathrm{~m}$, and so on. The relevant legs for the two contoured sections presented in this paper are marked in red on their respective SeaSoar survey track 


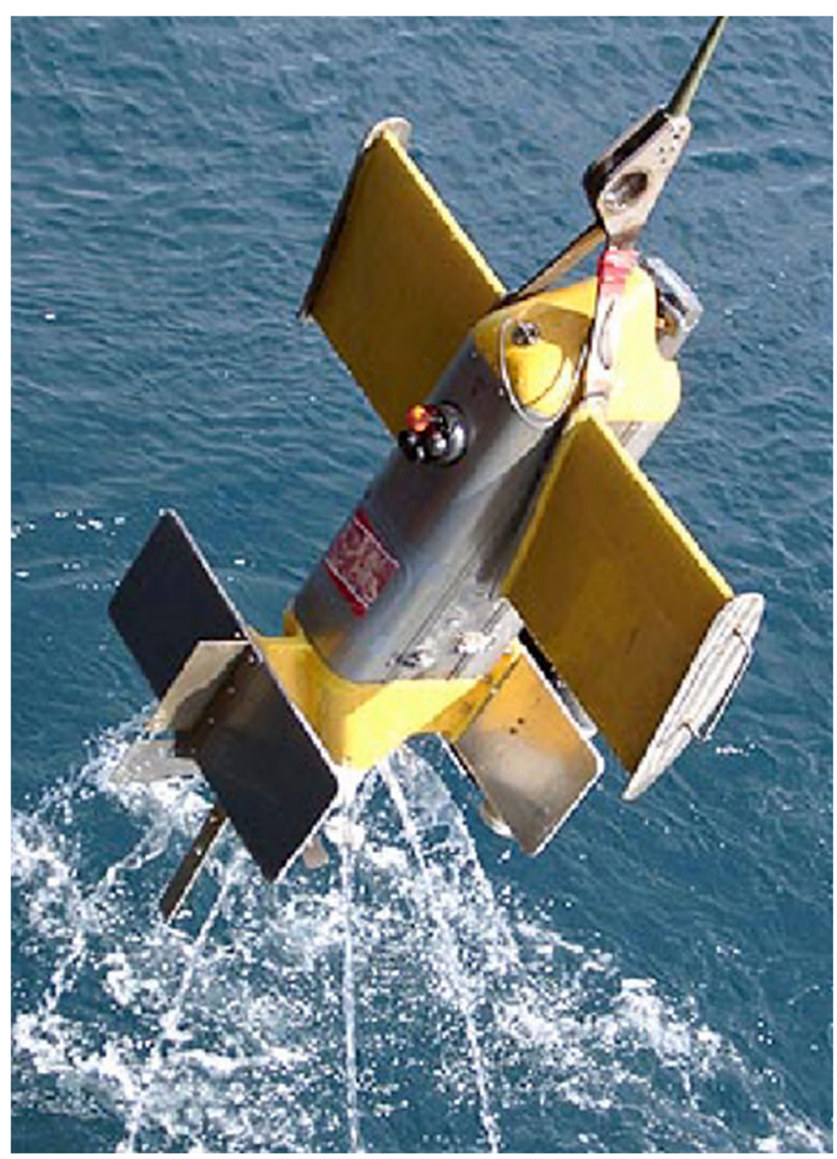

Fig. 2 A photograph of the re-developed SeaSoar vehicle used on the FISHES cruise

subduction mechanism for the rapid export of phytoplankton biomass to the deep ocean in a strained-out filamentary structure. In 2001, by June, the spring phytoplankton bloom had already happened and the euphotic upper ocean in the region was in a post-bloom low-nutrient concentration, near oligotrophic state. Here, as in most of the northern North Atlantic, the dominant phytoplankton species in the spring bloom are diatoms and it is often the depletion of silicate concentration rather than nitrate that ends the bloom (Brown et al. 2003). Nevertheless, satellite ocean colour images, and the combined analysis of in situ physical measurements with novel biological silica uptake experiments, indicated that a viable phytoplankton stock was being maintained in the frontal jet with new nutrients supplied by vertical velocities resulting from baroclinic instability processes (Allen et al. 2005).

Taking a lead from meteorology (Hoskins et al. 1985), traditionally PV is mapped on potential density surfaces (an equivalent of isentropic surfaces in meteorology) and used to highlight the contrast in characteristics of water masses, largely through differences in stratification, and by corollary, to identify waters of similar origin (Allen and Smeed 1996). However, mapping PV on a potential density surface within the pycnocline at the IFF resulted in the discovery of an unexpected filamentary pattern in the otherwise weakly variant stratification within the pycnocline. Once spotted, this pattern also became quickly apparent in directly observed variables. In this paper, direct observations of the filamentary processes drawing biological material down at the IFF will be presented. Furthermore, it will be shown that this filamentary structure is, to a first order, the result of the constraint on the water masses to play their part in the conservation of angular momentum.

\section{Observational analyses}

During the second leg of the FISHES (Færœs, Iceland, Scotland Hydrographic and Environmental Survey) cruise, RRS Discovery cruise 253 (Allen and Pollard et al. 2001b) in June 2001, three repeated high-resolution 'radiator'-style surveys were made of an area (approximately $90 \mathrm{~km}$ by $90 \mathrm{~km}$ ) of the IFF (Fig. 1). These surveys were carried out with the then recently re-developed SeaSoar vehicle (Allen et al. 2002), which (Fig. 2), when towed behind a ship at 8 10 knots, undulates over the top $\sim 450 \mathrm{~m}$ of the water column with a period of less than $10 \mathrm{~min}$. The data from the resulting 'saw-tooth' pattern are averaged into the equivalent of vertical profiles at 4-km intervals. Each survey path had six to nine track legs; these tracks ran in an approximately southwestnortheast and vice-versa direction during surveys 1 and 2 , whilst for survey 3 the tracks were carried out in the orthogonal southeast-northwest and vice-versa directions. Each survey took approximately 3 days, and a $24-\mathrm{h}$ period was allowed between surveys for biological sampling stations.

Amongst other instruments, the SeaSoar vehicle was fitted with a CTG (Chelsea Technologies Group) MiniPack CTD-F (Conductivity, Temperature, Depth, and Fluorimeter) and a CTG Fast Repetition Rate Fluorimeter (FRRF). In addition, RRS Discovery was fitted with two vessel-mounted acoustic Doppler current profilers (VM-ADCP), one operating at $150 \mathrm{kHz}$ and another at $75 \mathrm{kHz}$, to determine the absolute velocity profile of the water flow over the top $500 \mathrm{~m}$ of the water column (Allen and Pollard et al. 2001b).

Data from the three repeated SeaSoar surveys, both from the SeaSoar vehicle and the VM_ADCPs, were interpolated to a three-dimensional regular grid using a $20-\mathrm{km}$ Gaussian weighting, following Allen and Smeed (1996). For each survey, geostrophic currents derived from the interpolated hydrography were referenced to a horizontally non-divergent stream function fitted to $150-\mathrm{KHz}$ VM-ADCP horizontal velocity components from a water depth of $\sim 250 \mathrm{~m}$. The stream functions, $\psi$, defined in a conventional fashion as $u=-{ }^{\partial \psi} / \partial y, v={ }^{\partial} \psi / \partial x$, were calculated solving $\nabla^{2} \psi=\left({ }^{\partial v} / \partial x^{-}{ }^{\partial u} / \partial y\right)=\zeta$, the vertical component of relative vorticity (Fig. 3), for Neumann boundary conditions, ${ }^{\partial \psi} / d n=\mathbf{n} \times \mathbf{k} \cdot \mathbf{u}$, where $\mathbf{u}=(u, v)$ is the horizontal VM$\mathrm{ADCP}$ velocity vector, $\mathbf{n}$ is the unit vector perpendicular to the boundary, and $\mathbf{k}$ is the unit vertical vector (Allen and Smeed 
Fig. 3 Relative vertical vorticity mapped at the VM-ADCP reference level, $\sim 250 \mathrm{~m}$

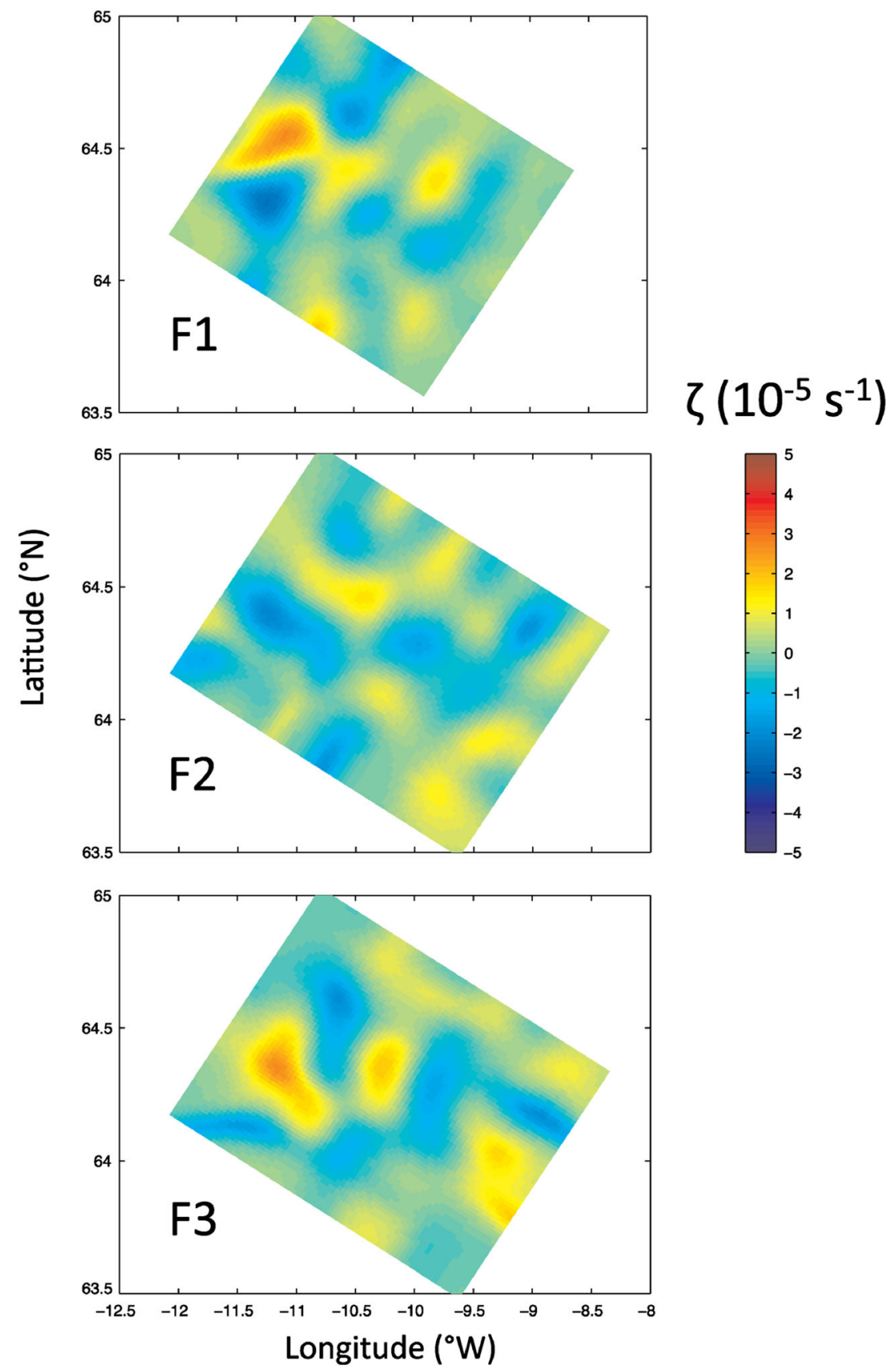

1996; Allen et al. 2001a). At the latitude of the IFF, the local Coriolis parameter is $\sim 1.4 \times 10^{-4} \mathrm{~s}^{-1}$, and therefore from Fig. 3, we can see that Rossby numbers, $\varepsilon={ }^{U} / f L=\zeta / f$, greater than 0.3 may be expected. Indeed, Allen and Smeed (1996) suggested that a Rossby number as large as 0.8 could be defined in some regions of the IFF. More recently, Thomas et al. (2008) highlighted the existence of sub-mesoscale features at Rossby numbers of order 1 .

On the temporal scale of days and spatial scale of 1$100 \mathrm{~km}$, water particles move along, and with, surfaces of constant potential density, isopycnal surfaces. The 27.75 sigma-0 $\left(\sigma_{0}\right)$ isopycnal surface lies at the centre of the pycnocline and bottom of the halocline in the IFF region of the northern N. Atlantic (Fig. 4). Across a frontal zone, it is in the pycnocline where we expect the most effective isopycnal transport to occur. It is therefore intuitive to map physical and biological properties on the $27.75 \sigma_{0}$ surface if our goal is to look at transports driven by instability (Allen et al. 2001a; Allen et al. 2005) (Fig. 5) rather than the contrast between large-scale water masses (Allen and Smeed 1996).

If we were to assume that phytoplankton can be considered passive with respect to the three-dimensional fluid motions (Fielding et al. 2001), then it is instructive to look at proxies for the observation of phytoplankton on isopycnal surfaces 
Fig. 4 Contoured sections of a potential temperature, $\mathbf{b}$ salinity, $\mathbf{c}$ fluorescence yield (as nominal chlorophyll concentration) and $\mathbf{d}$ Brunt-Väisälä frequency for leg $\mathrm{E}$ of SeaSoar survey 2 (middle track leg, middle top map in Fig. 1).

Annotated contour lines of constant density, isopycnals, are overplotted. The 27.70 and $27.80 \sigma_{0}$ isopycnals are shown in bold to highlight the density layer discussed in the text

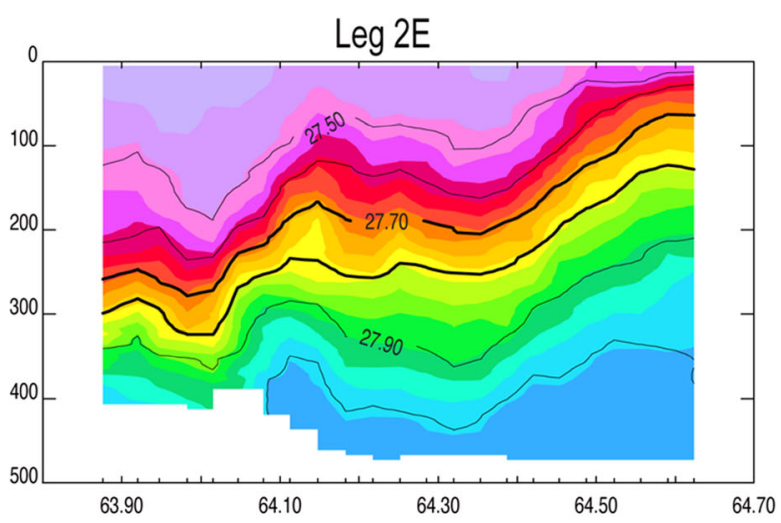

Pot. temp. $\left({ }^{\circ} \mathrm{C}\right)$
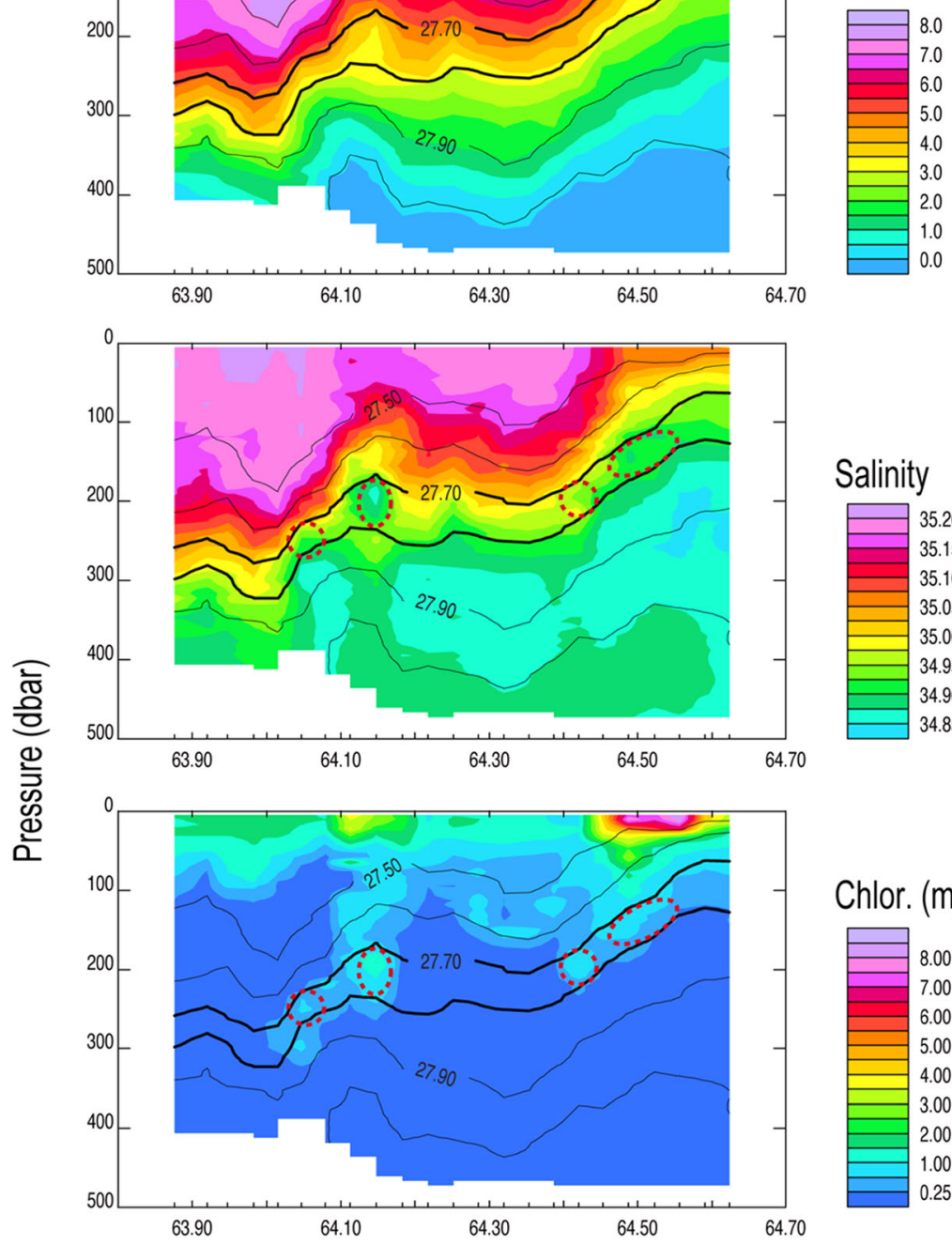

Salinity

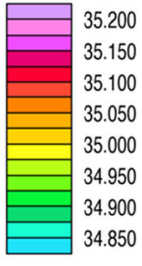

Chlor. $\left(\mathrm{mg} \mathrm{m}^{-3}\right)$
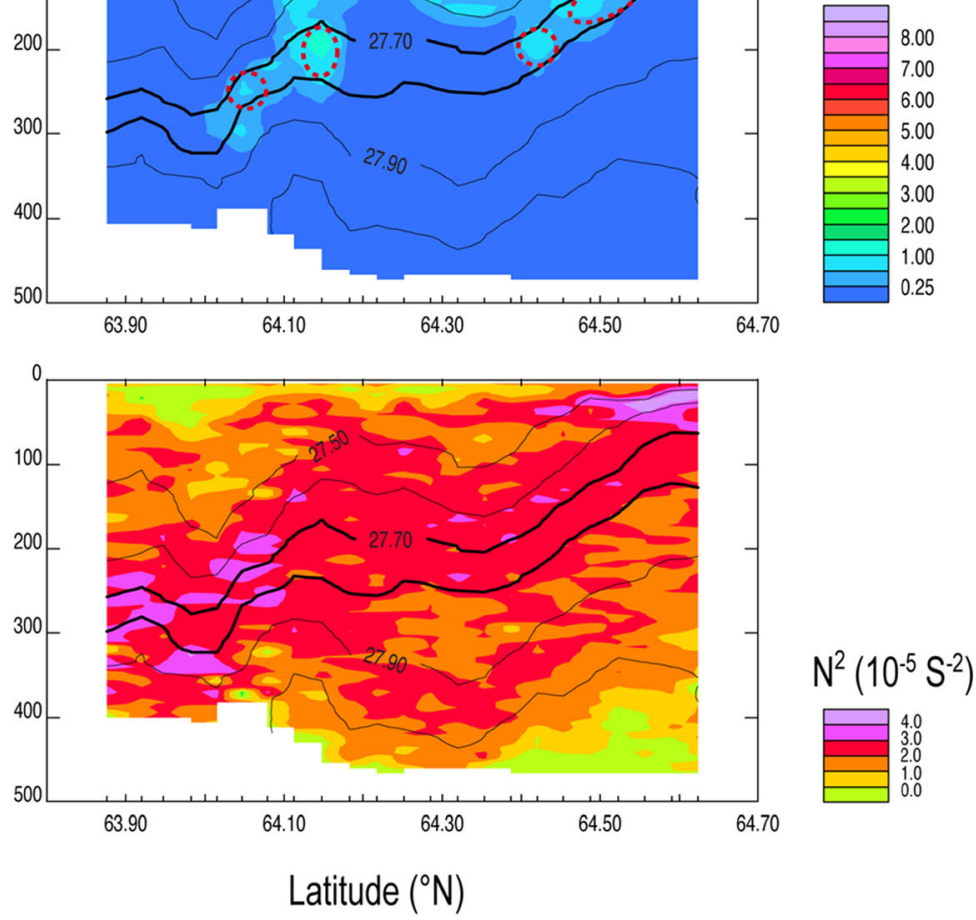

(Allen et al. 2001a). Mapping fluorescence yield on the 27.75 $\sigma_{0}$ surface (Fig. 6), we see the highest values where this density surface outcrops into the euphotic shallow mixed layer on the north (cold) side of the convoluted frontal boundary (Fig. 7). But our analysis also shows the existence of thin tongues of much lower fluorescence yield at depths drawn around the 
Fig. 5 Salinity mapped on the $27.75 \sigma_{0}$ surface

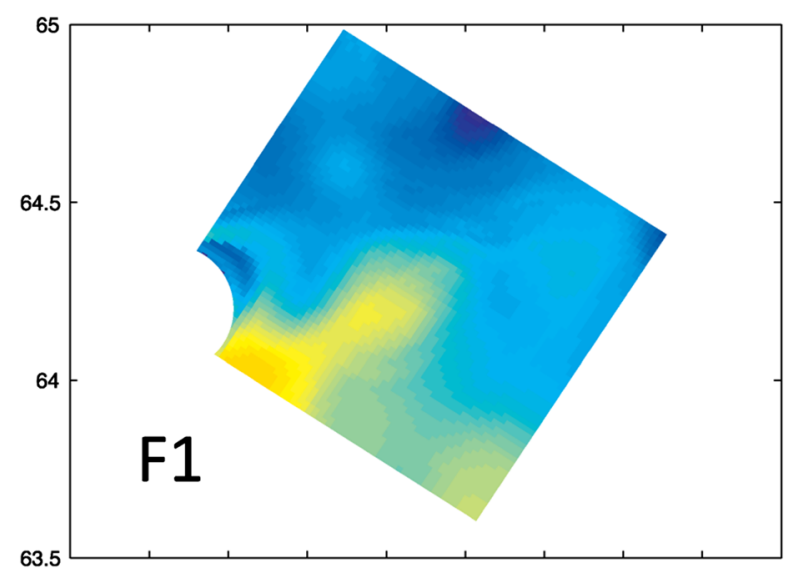

Salinity
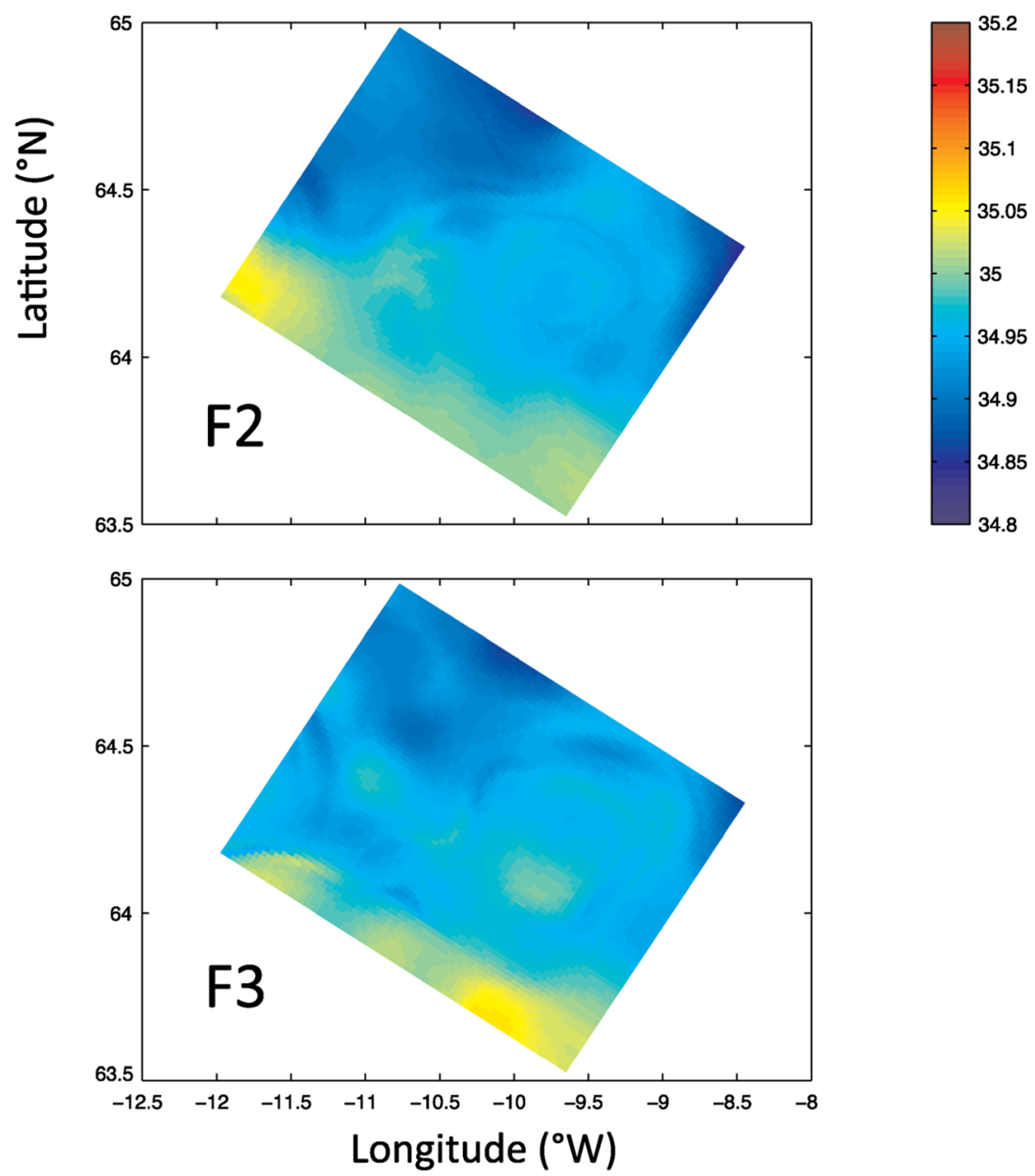

anticyclonic vortices of the frontal boundary. These filamentary structures are even more apparent if we map the property $F_{V} / F_{M}$ (Moore et al. 2005) from the FRRF instrument on the same density surface (Fig. 8). The maximum photochemical quantum efficiency, $\mathrm{F}_{\mathrm{V}} / \mathrm{F}_{\mathrm{M}}$, can be thought of as a proxy for phytoplankton viability, and therefore, it is somewhat independent of their concentration in the water. If phytoplankton cells exist and are still viable, i.e. capable of photosynthesis, the FRRF stimulates a response. Flashing at up to $200 \mathrm{kHz}$, the FRRF measures the instantaneous fluorescence yield until saturation $F_{M}$, to which saturation curves are fitted, and $F_{V} / F_{M}$ is determined (Kolber et al. 1998). Defined as $0.1 \%$ surface irradiance, photic depths were typically $30-60 \mathrm{~m}$ in the IFF region, and typically around twice the mixed layer depth (Brown et al. 2003). So in Fig. 8, we see that these filaments contain viable phytoplankton cells to depths in excess of the photic depth and beneath the thermocline (Figs. 4 and 7). Furthermore, we see that there is an annular nature to these 
Fig. 6 Fluorescence yield (as nominal chlorophyll

concentration) mapped on the $27.75 \sigma_{0}$ surface

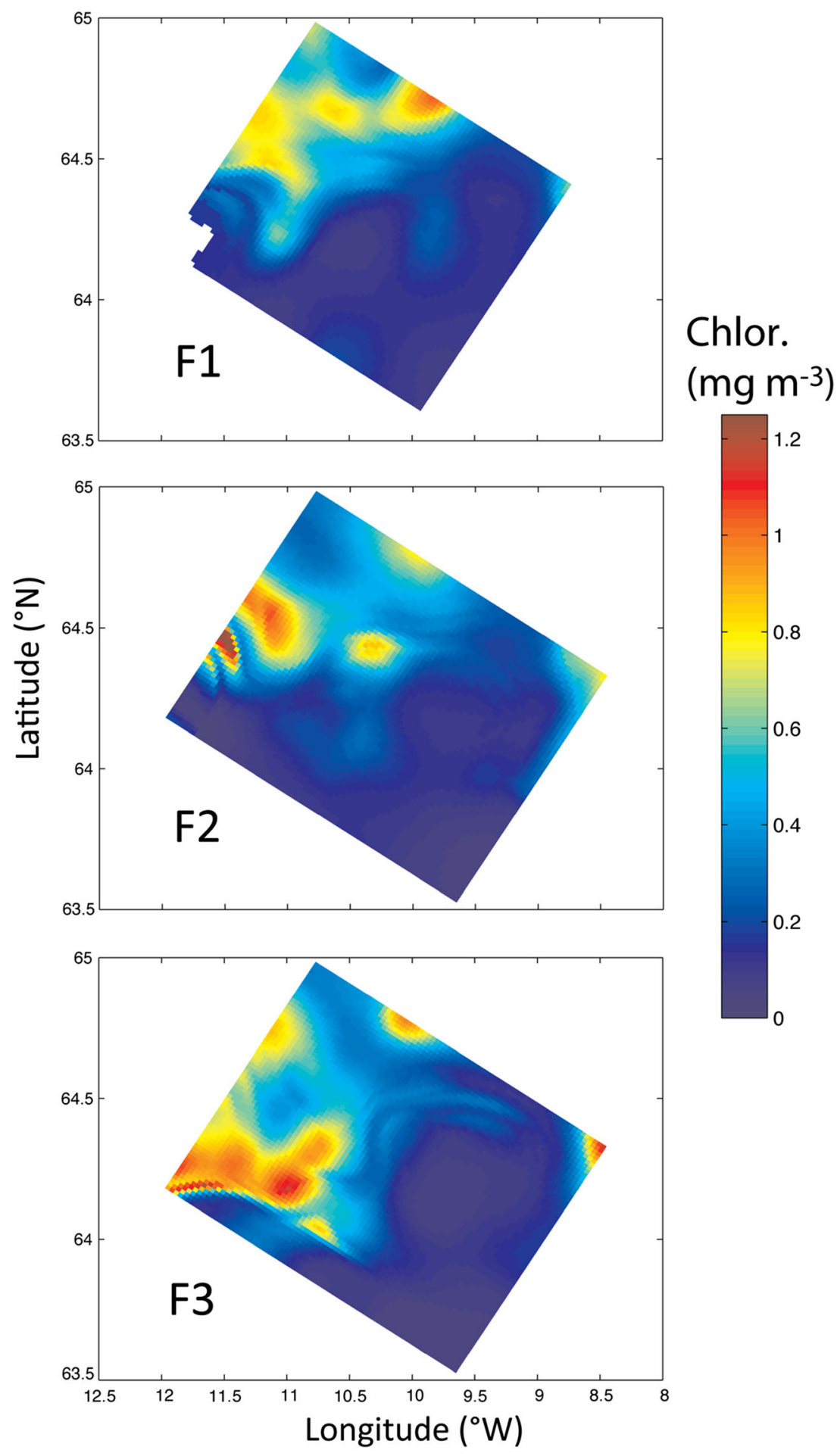

filaments associated with the circular structures of the eddies and instabilities.

Woods (1988) and Strass and Woods (1988) demonstrated the importance of considering Rossby-Ertel potential vorticity (PV) in understanding observations of marine ecology. In the absence of dissipation and external forces, PV is conserved (Rossby 1940; Ertel 1942), following a fluid particle, and therefore following flow along density surfaces. PV was calculated conventionally as $P V=-\left(f+\zeta_{g}-f F\right) N^{2} / g$ where the Brunt-Väisälä frequency is given by $N^{2}=-g / \rho \partial \rho / \partial z$ and $F=1 / N_{N^{2}}\left[(\partial \mathrm{u} / \partial \mathrm{z})^{2}+(\partial \mathrm{v} / \partial \mathrm{z})^{2}\right]$ is the Froude number (Pollard and Regier 1992; Allen and Smeed 1996; Allen et al. 2001a). The referenced absolute geostrophic velocities, discussed earlier, were used to calculate the geostrophic 
Fig. 7 Mapped pressure in decibars of the $27.75 \sigma_{0}$ surface

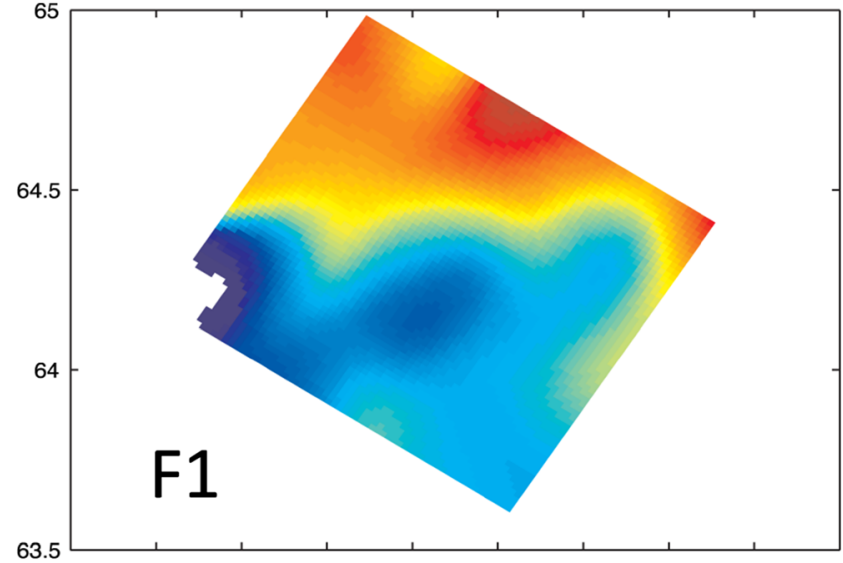

Pressure (dbar)
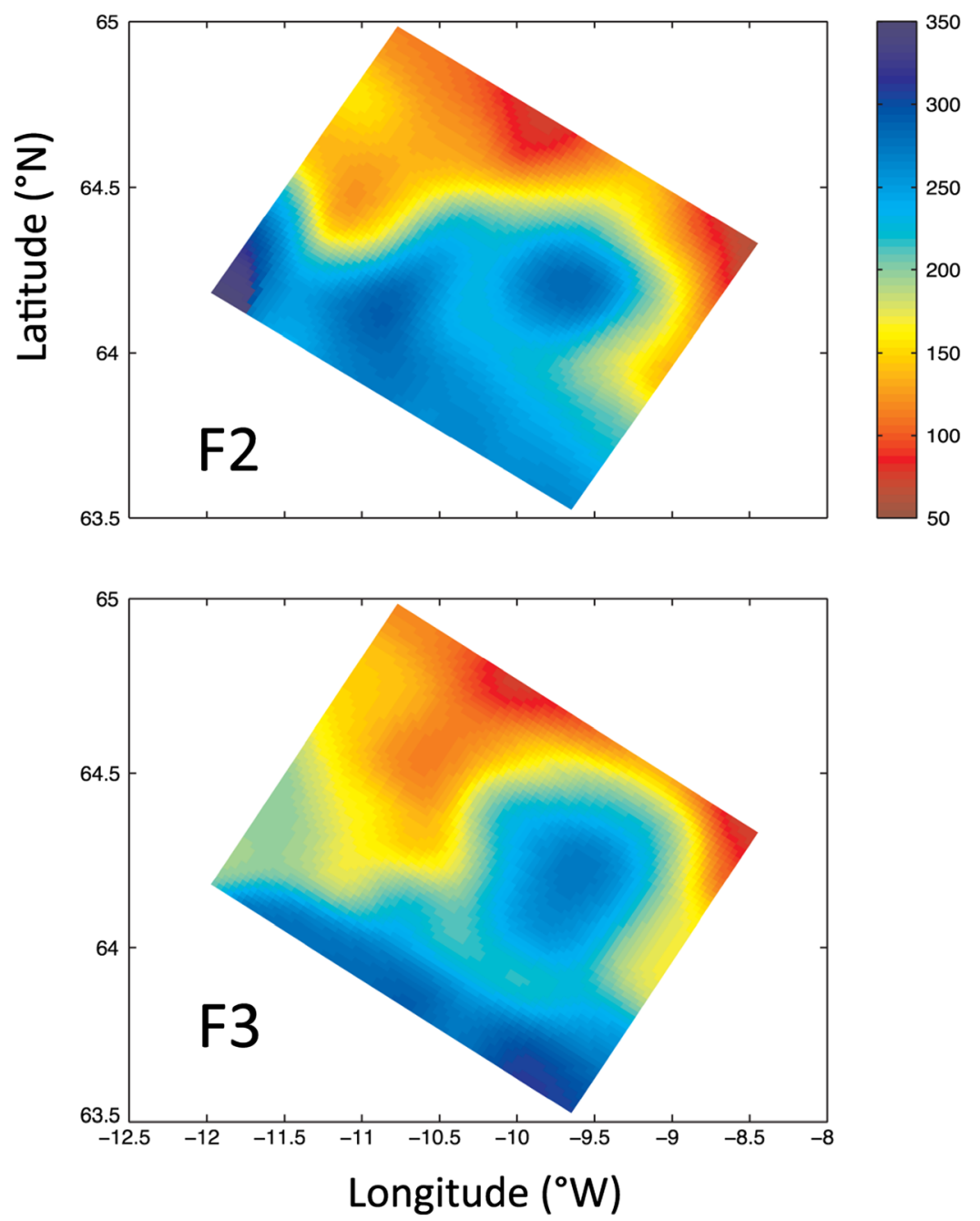

relative vorticity, $\zeta_{g}$, component of PV, where $\zeta_{g}=\left({ }^{\partial} v_{g} / \partial x-\partial u_{g} / \partial y\right)$. In Fig. 9, we plot PV on the $27.75 \sigma_{0}$ surface; again, we see a rotational pattern of alternating streaks of lower and higher vorticity aligned with the circular structure of the unstable eddy structures of the front and coincident with the filaments found in the fluorescence yield and $\mathrm{F}_{\mathrm{V}} / \mathrm{F}_{\mathrm{M}}$ signals discussed above. Significant confidence in the analyses of these data is achieved by remembering that the third SeaSoar survey was carried out with track legs orthogonal to those in the previous two surveys; the appearance and coincidence of the filaments are clear throughout the three surveys, indicating that the inherent anisotropy in sampling resolution does not significantly affect the appearance of the filaments. 
Fig. 8 Maximum photochemical quantum efficiency, $\mathrm{F}_{\mathrm{V}} / \mathrm{F}_{\mathrm{M}}$, mapped on the $27.75 \sigma_{0}$ surface
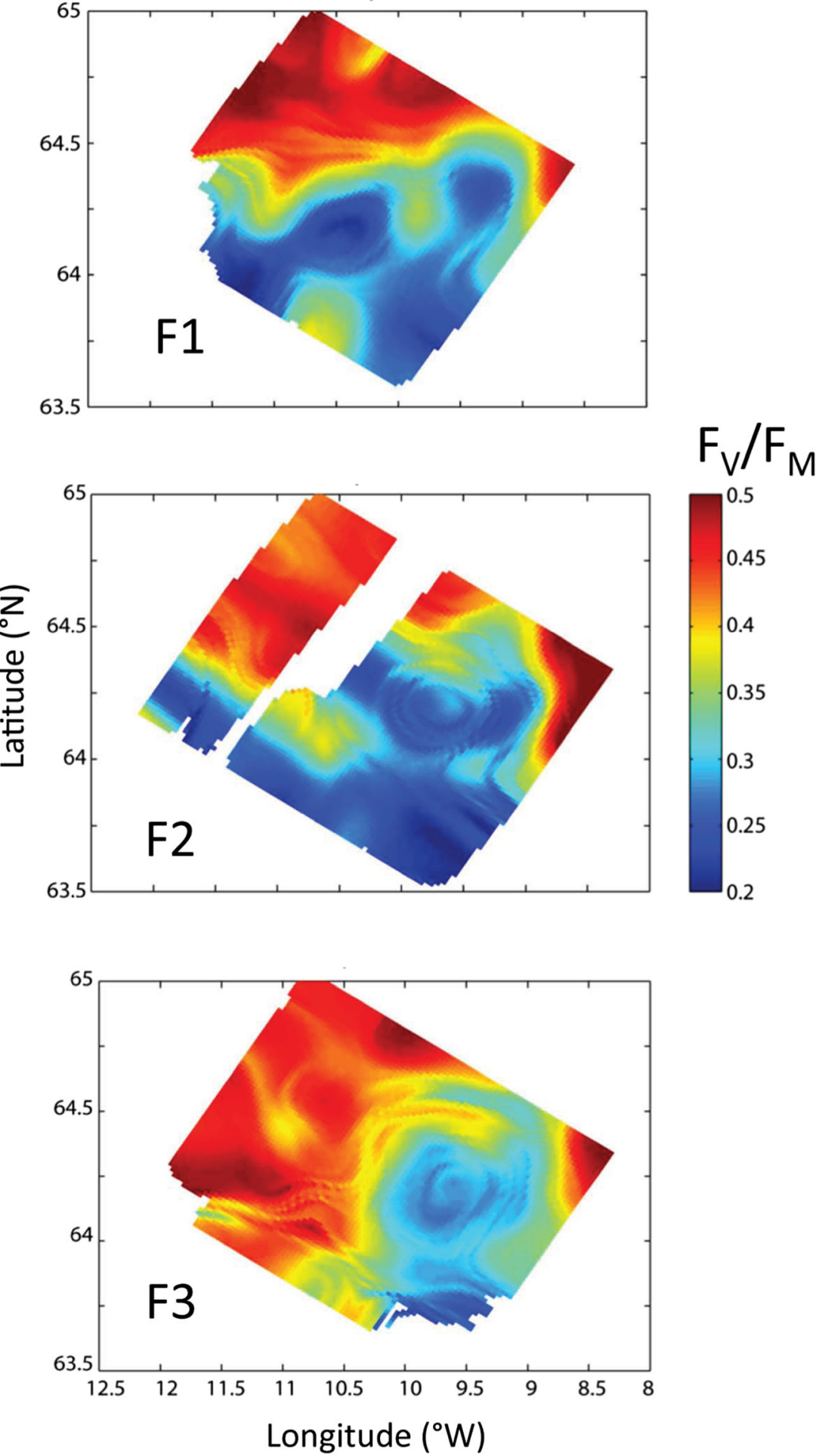

As discussed earlier, Allen et al. (2005) presented the 12day evolution of the diagnosed QG vertical velocity field from these high-resolution surveys over the Iceland Færœs Ridge (Fig. 10). The ubiquity of the motion was clear, and the effect on biomass distribution in a vertical section across the front was presented and discussed. However, the discovery of filaments on density surfaces in line with the circular structure of eddies, and coincident with 'rings' of alternating lower and higher vorticity, demands us to look at vertical sections again. In Fig. 4, we presented contoured sections of fluorescence yield and salinity for a section through the anti-cyclonic eddy during the second fine-scale SeaSoar survey. There are two 
Fig. 9 Potential vorticity in units of $10^{-9} \mathrm{~m}^{-1} \mathrm{~s}^{-1}$ mapped on the $27.75 \sigma_{0}$ surface

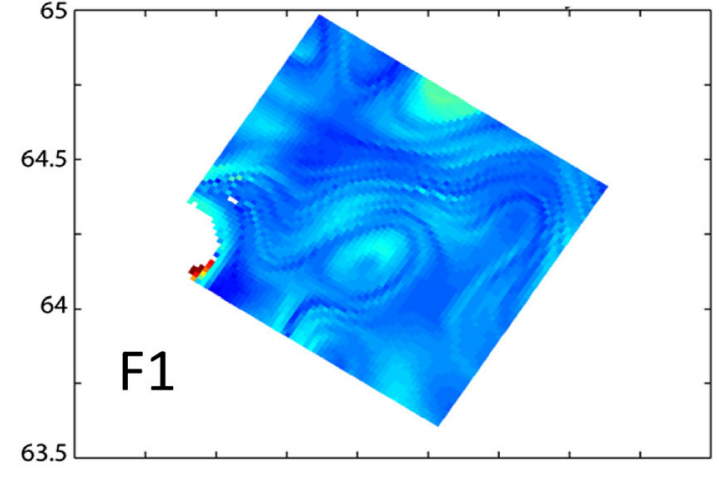

PV
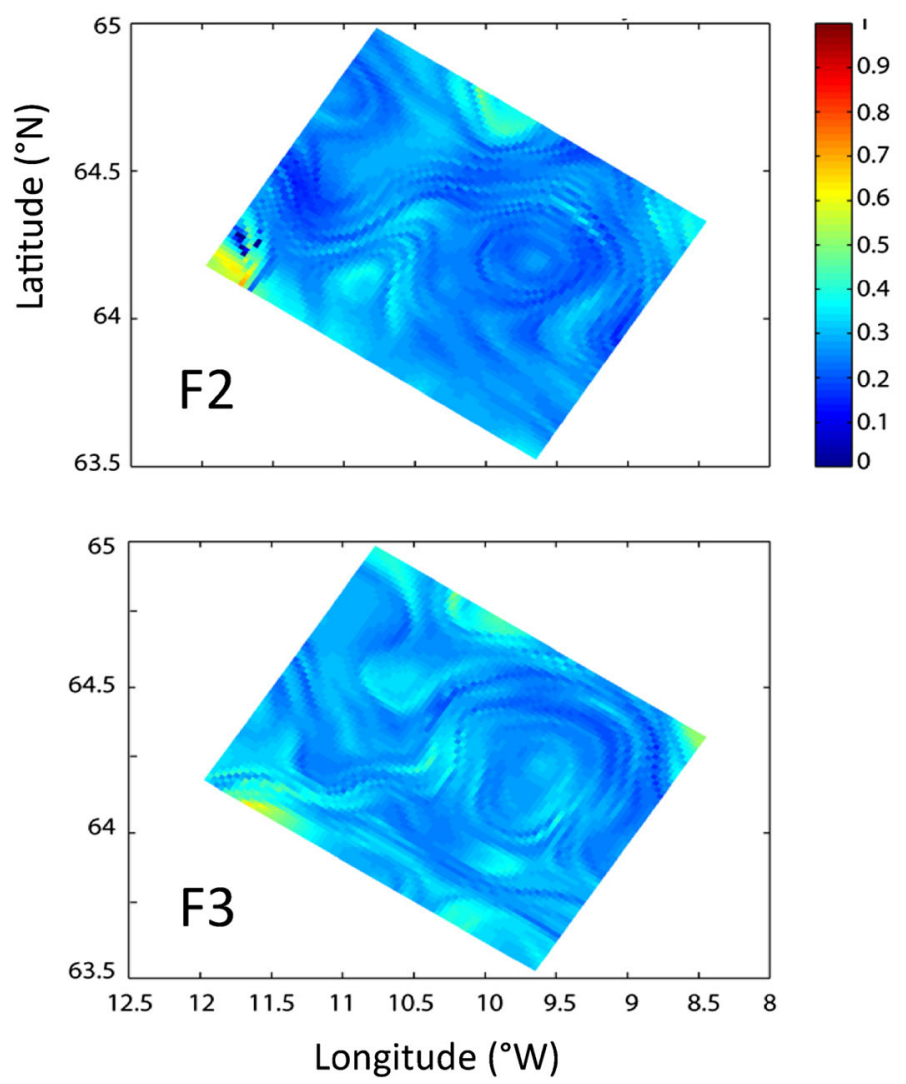

clear areas of fluorescence yield apparently subducted below the pycnocline/halocline, one around $64.1^{\circ}$ North and the other around $64.5^{\circ}$ North. The contouring gives the impression that these areas of fluorescence yield make up two tongues of biological material drawn down or sinking out of the base of the mixed layer in the plane of the contoured section. However, if we look carefully at the peaks in fluorescence at depth, particularly those around $27.75 \sigma_{0}$, highlighted in the figure by the four red dashed ellipses, we can see that they are associated with water of different salinities, from left to right, 34.90 and 34.85 , and 34.90 and 34.88 . Thus, the credibility of the tongues of subducted or sinking material in the plane of the section begins to look rather weak. In fact, these patches at around $27.75 \sigma_{0}$ match up with the filaments mapped on this density surface (Figs. 6 and 8 ) as discussed above; i.e. they are individually the filaments of biological material extending in the plane perpendicular to the section. Indeed, if we look again at salinity on the $27.75 \sigma_{0}$ surface (Fig. 5), we again see the repeated pattern of these annular filaments as described earlier, as a passive water tracer.

Perhaps we should not be too surprised at the existence of filamentary structures at scales below $10 \mathrm{~km}$. Although Allen et al. (1994) indicated fastest growing wavelengths of instability around $40-70 \mathrm{~km}$, they also showed that a Rossby radius of deformation, $R_{0}={ }^{1} / \sqrt{g^{\prime} H}$, could be derived as small as $\sim 8 \mathrm{~km}$ largely due to the bathymetric locking of the front zone to the Iceland-Færœs ridge, rising from in excess of $2000 \mathrm{~m}$ to shallowest depths of $\sim 400 \mathrm{~m}$. McWilliams (2016) teaches us to expect the deformation radius of baroclinic instability at sub-mesoscales to be considerably less than these estimates for the mesoscale. 
Fig. 10 QG vertical velocity in units of metres per day mapped on the $27.75 \sigma_{0}$ surface. Dotted lines show the positions of the front defined as a depth of $\sim 200 \mathrm{~m}$ for the $27.75 \sigma_{0}$ isopycnal

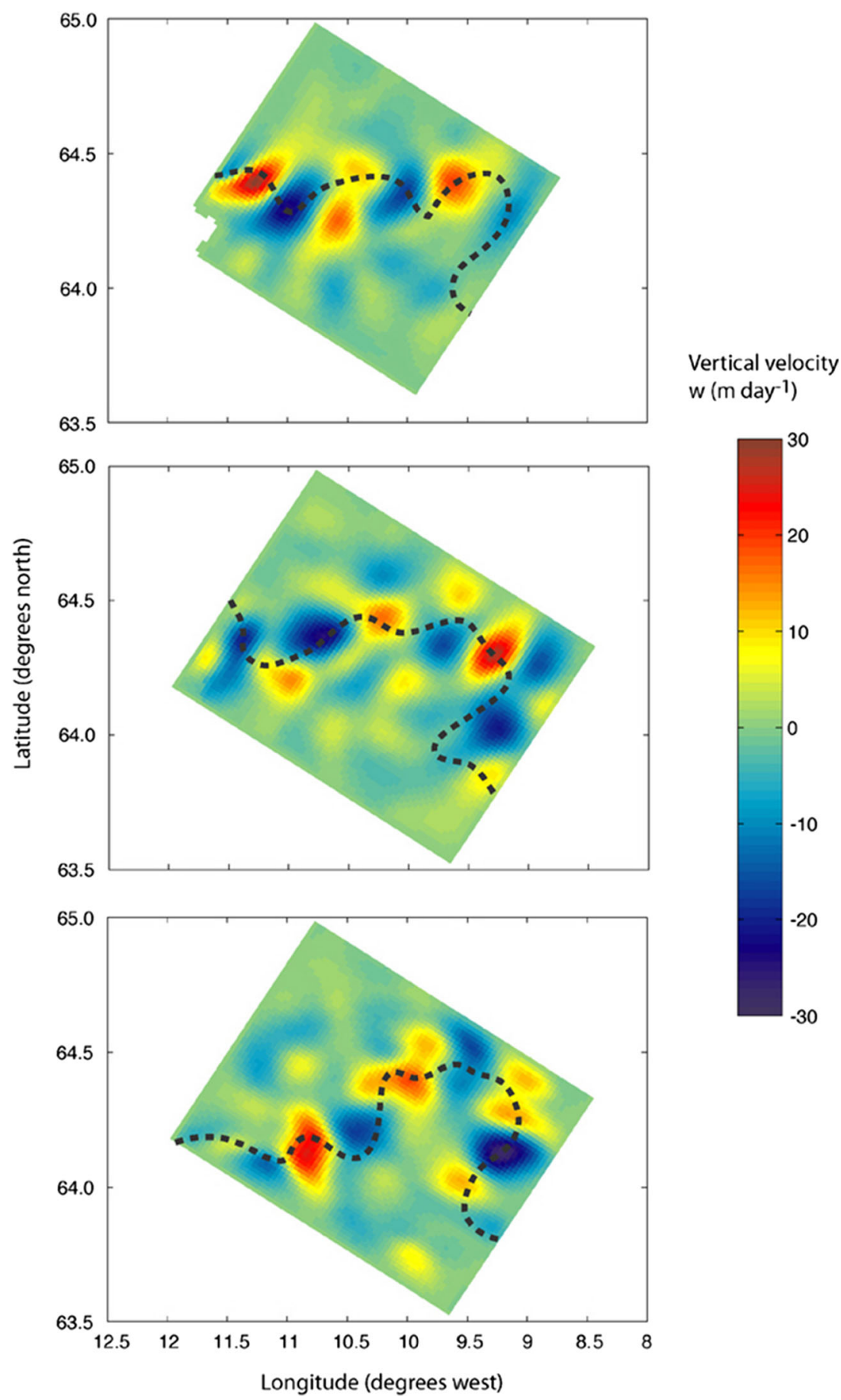

\section{Speculative discussion}

Pidcock et al. (2016) have shown how difficult it is to integrate up from mesoscale and smaller-scale observations to a basinscale understanding of the significance of dynamic processes. Our observations have shown that there is a mechanism by which phytoplankton can be exported from the euphotic zone along filaments associated with the quasi-balanced instability of eddies where PV still needs to be conserved on isopycnal surfaces. So if we consider an annular tube representing one of these constant vorticity filaments, according to the typical cross-sectional dimensions of the red dotted circles in Fig. 3, this filament would have a rather oblate elliptical cross section of around $4000 \mathrm{~m}$ by $40 \mathrm{~m}$, i.e. a cross-sectional area of order $5 \times 10^{5} \mathrm{~m}^{2}$. With typical VM-ADCP-measured radial currents of order $30 \mathrm{~cm} \mathrm{~s}^{-1}$ (Allen et al. 1994), and a difficult-toestimate but conservative (Figs. 4 and 7) vertical gradient of order 0.002 , this would imply a typical downward vertical 
Fig. 11 Contoured sections of salinity and fluorescence yield (as nominal chlorophyll concentration) for leg $\mathrm{E}$ of SeaSoar survey 3 (second from bottom leg, right top map in Fig. 1). Annotated contour lines of constant density, isopycnals, are over-plotted. The 27.70 and 27.80 $\sigma_{0}$ isopycnals are shown in bold to highlight the density layer discussed in the text

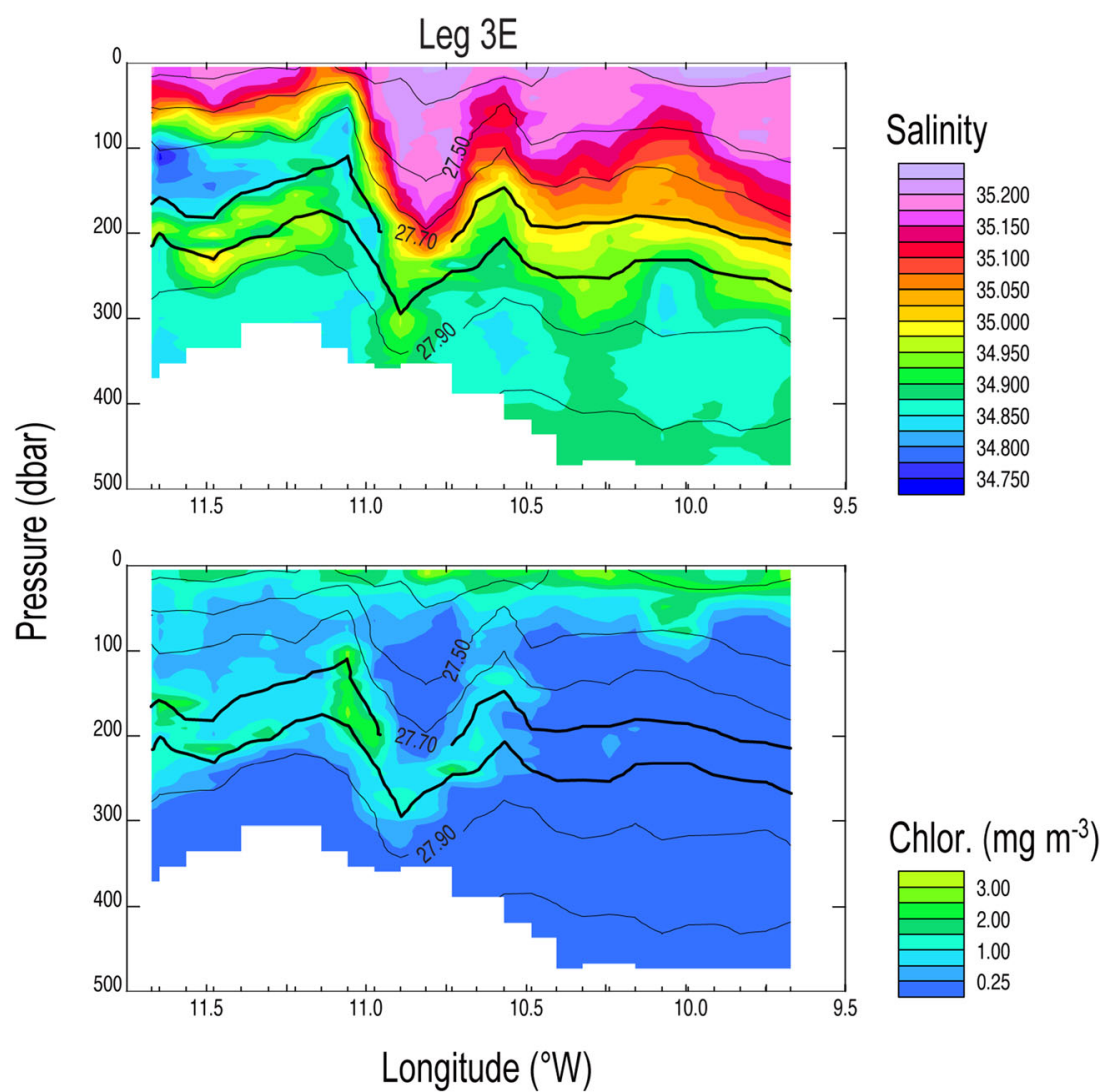

velocity of $\sim 50 \mathrm{~m} \mathrm{day}^{-1}$ and transport of $300 \mathrm{~m}^{3} \mathrm{~s}^{-1}$. This is reasonably consistent with the $30 \mathrm{~m}$ day $^{-1}$ determined by Allen et al. (2005) (Fig. 10) and the 60-90 m day ${ }^{-1}$ determined during the previous cruise in 1990 (Allen and Smeed 1996).

Considering euphotic zone biomass concentrations of $\sim 30 \mathrm{mg} \mathrm{C} \mathrm{m}^{-3}$ (Brown et al. 2003), this would imply a potential export along a filament of $\sim 9 \mathrm{~g} \mathrm{C} \mathrm{s}^{-1}$, or $\sim 70 \mathrm{tyear}^{-1}$ for a 3-month growth season. Now the question is how this stacks up as a globally important figure. If we take a 2GT year ${ }^{-1}$ global export figure, then we would need $\sim 28$ million of these filaments, covering an ocean area of $\sim 14$ million $\mathrm{km}^{2}$. These all sound like very big numbers, but this area is only approximately $4 \%$ of the surface area of the ocean, and therefore, it is not unreasonable to suggest that the ubiquity of eddies makes this transport mechanism a potentially significant component of export production.

\section{Conclusions}

For the second leg of FISHES, RRS Discovery cruise 253, real-time forecast modelling (Popova et al. 2002) provided both a means for rapid assimilation of the datasets and a medium in which to objectively determine optimum sampling strategies (Rixen et al. 2003). This resulted in the three highresolution SeaSoar sampling surveys presented and discussed above; the near real-time fast model survey simulations drove a reversal in the overall survey direction in survey 2 , from east to west rather than from west to east as in survey 1 , and of particular note, they drove the orthogonality of the track legs in the third survey and the overall direction of this survey from north to south.

Much can be learned from knowledge of PV without performing a full inversion (Hoskins et al. 1985; Allen et al. 1994). We have presented observations here of a filamentary structure in the PV field, when mapped on a density surface that crosses the frontal boundary, i.e. on which there is no dramatic change in stratification. Furthermore, we have observed that these structures in PV coincide with filaments in the passive fluorescence yield, active $\mathrm{F}_{\mathrm{V}} / \mathrm{F}_{\mathrm{M}}$, and the salinity. We have presented the observation of photosynthetic biological material being advected downwards around unstable anticyclonic frontal meanders, in the form of filamentary structures resulting from a requirement to conserve local angular momentum expressed here as PV.

We made an early assumption that at our observation scales, phytoplankton cells were passively advected around with the water, i.e. along and with isopycnal surfaces. Rodriguez et al. (2001) showed that only small upward vertical motions in the water column $\left(<5 \mathrm{~m} \mathrm{day}^{-1}\right)$ were sufficient to support the size range of the bulk of ocean phytoplankton cells. Moore et al. (2005) used a combination of FRRF data and pigment analysis to conclude that the post-bloom IFF frontal region was supported by a mixture of diatoms and flagellates. Large 
aggregated unhealthy diatom cells may sink considerably faster (Turner 2002), greater than $100 \mathrm{~m} \mathrm{day}^{-1}$ perhaps, but such processes would not line up with density surfaces or flow streamlines as found in our presented observations and generally throughout the three SeaSoar surveys (Fig. 11).

Both the forecast modelling and the repeated SeaSoar surveys during leg 2 of the FISHES cruise showed the instability of the IFF to be dominated by $50-60-\mathrm{km}$ anticyclonic meanders from the warm side of the front. This had a significant biological consequence; the surface waters were weakly stratified to over $100 \mathrm{~m}$ within the anticyclonic meanders and on the southern side of the IFF in general, holding back the spring bloom which had already passed and was now largely exhausted on the north, cyclonic, side of the front. Indeed, biological production in the convoluted surface frontal boundary was shown to be supported by the upwelling of nutrients into the photic layer (Allen et al. 2005) by the complimentary exchange of water to that presented here.

In our simple speculative constructional model of the filamentary structures, we show that it is not difficult to consider that these processes could provide a significant component of the global export production budget. Omand et al. (2015) made a similar conclusion from a modelling study motivated by glider observations of enhanced biological proxies at an eddy in the N. Atlantic. Some approaches to parameterise these scales of instability, often referred to as the sub-mesoscale, have been published (Bachman et al. 2017; Fox-Kemper et al. 2011); however, we propose that more targeted observation is urgently required to test theories and explore interdisciplinary impacts. Further glider instrumentation will rapidly increase the rate of observation of these processes (Ruiz et al. 2009; Omand et al. 2015) and our ability to understand their global importance. Furthermore, the dataset presented here is not recent, dating to 2001; we would encourage other groups to take another look at any historical high-resolution datasets they may have and test the ubiquity of our observations.

Acknowledgements I thank all my colleagues who, over several years, persuaded me to write up this work; they are too many to name individually, with the particular exception of Dr. Adrian Martin. I express my deepest gratitude to Ms Ranji Goddard for her untiring grammatical and presentational support; and for listening endlessly. I am also indebted to the anonymous reviewers of my manuscript for their helpful comments, suggestions and discussions.

Open Access This article is distributed under the terms of the Creative Commons Attribution 4.0 International License (http:// creativecommons.org/licenses/by/4.0/), which permits unrestricted use, distribution, and reproduction in any medium, provided you give appropriate credit to the original author(s) and the source, provide a link to the Creative Commons license, and indicate if changes were made.

\section{References}

Allen JT, Smeed DA (1996) Potential vorticity and vertical velocity at the Iceland Færœs front. J Phys Oceanogr 26(12):2611-2634

Allen JT, Smeed DA, Chadwick AL (1994) Eddies and mixing at the Iceland Færœs Front. Deep Sea Res 1 41(1):51-79

Allen JT, Smeed DA, Tintore J, Ruiz S (2001a) Mesoscale subduction at the Almeria-Oran front. Part1: Ageostrophic flow. J. Mar. Sys. 30:263-285

Allen JT and Pollard RT et al. (2001b) RRS Discovery Cruise 253, 4 May 2001-20 June 2001, Færœs, Iceland, Scotland Hydrographic and Environmental Survey, (FISHES). Southampton Oceanography Centre, Cruise Report No.37, 206 pp

Allen J, Dunning J, Cornell V, Moore M, Crisp N (2002) Operational oceanography using the 'new' SeaSoar ocean undulator. Sea Tech 43(4):35-40

Allen JT, Brown L, Sanders R, Moore CM, Mustard A, Fielding S, Lucas M, Rixen M, Savidge G, Henson S, Mayor D (2005) Diatom carbon export enhanced by silicate upwelling in the northeast Atlantic. Nature 437(7059):728-732. https://doi.org/10.1038/nature03948

Bachman SD, Fox-Kemper B, Taylor JR, Thomas LN (2017) Parameterization of frontal symmetric instabilities. I: Theory for Resolved Fronts. Ocean Model 109:72-95. https://doi.org/10. 1016/j.ocemod.2016.12.003

Brown L, Sanders R, Savidge G, Lucas CH (2003) The uptake of silica during the spring bloom in the Northeast Atlantic Ocean, Limnol Oceanogr 48(5):1831-1845. https://doi.org/10.4319/lo.2003.48.5.1831

Ertel H (1942) Ein Neuer hydrodynamischer Wirbelsatz. Meteorol Z 59: 271-281

Fielding S, Crisp N, Allen JT, Hartman MC, Rabe B, Roe HSJ (2001) Mesoscale subduction at the Almeria-Oran front. Part 2: biophysical interactions. J Mar Sys 30:287-304

Fox-Kemper B, Danabasoglu G, Ferrari R, Griffies SM, Hallberg RW, Holland MM, Maltrud ME, Peacock S, Samuels BL (2011) Parameterization of mixed layer eddies. III: implementation and impact in global ocean climate simulations. Ocean Model 39:6178. https://doi.org/10.1016/j.ocemod.2010.09.002

Hallock ZR (1985) Variability of frontal structure in the southern Norwegian Sea. J Phys Oceanogr 15:1245-1254

Hoskins BJ, Draghici I, Davies HC (1978) A new look at the $\omega$-equation. Quart J Roy Meteor Soc 104:31-38

Hoskins BJ, McIntyre ME, Robertson AW (1985) On the use and significance of isentropic potential vorticity maps. Quart J Roy Met Soc 111(470):877-946

Killworth PD, Paldor N, Stern ME (1984) Wave propagation and growth on a surface front in a two layer geostrophic current. J Mar Res 42:761-785

Kolber ZS, Prášil O, Falkowski PG (1998) Measurements of variable chlorophyll fluorescence using fast repetition rate techniques: defining methodology and experimental protocols. Biochim Biophys Acta 1367:88-106

Lapeyre G, Klein P (2006) Impact of the small-scale elongated filaments on the oceanic vertical pump. J Mar Res 64:835-851

Levy M, Klein P, Treguier A-M (2001) Impact of sub-mesoscale physics on production and subduction of phytoplankton in an oligotrophic regime. J Mar Res 59:535-565

Mahadavan A (2015) Impact of submesoscale physics on primary productivity of plankton. Ann Rev Mar Sci 8: 161-84. https://doi.org/ 10.1146/annurev-marine-01081-015912

McWilliams JC (2016) Submesoscale currents in the ocean. Proc R Soc A 472:20160117. https://doi.org/10.1098/rspa.2016.0117

Meincke J (1978) On the distribution of low salinity intermediate waters around the Færœs. Deutsche Hydrographische Zeitschrift 31:50-64

Moore CM, Lucas MI, Sanders R, Davidson R (2005) Basin-scale variability of phytoplankton bio-optical characteristics in relation to bloom state and community structure in the Northeast Atlantic. Deep Sea Res I 52(3):401-419 
Omand MM, D’Asaro EA, Lee CM, Perry MJ, Briggs N, Cetinić I, Mahadavan A (2015) Eddy-driven subduction exports particulate organic carbon from the spring bloom. Science 348:222. https:// doi.org/10.1126/science. 1260062

Pidcock REM, Martin AP, Painter SC, Allen JT, Srokosz MA, Forryan A, Stinchcombe M, Smeed DA (2016) Quantifying mesoscale-driven nitrate supply: a case study. Glob Biogeochem Cycles. https://doi. org/10.1002/2016GB005383

Pollard RT, Regier LA (1992) Vorticity and vertical circulation at an ocean front. J Phys Oceanogr 22:609-625

Popova EE, Srokocz MA, Smeed DA (2002) Real time forecasting of biological and physical dynamics at the Iceland Færœs Front in June 2001. Geophys Res Lett 29(4):14-1-14-4. https://doi.org/10. 1029/2001GL013706

Read JF, Pollard RT (1992) Water masses in the region of the Iceland Færœs front. J Phys Oceanogr 22:1365-1378

Rixen M, Allen JT, Alderson S, Cornell V, Crisp N, Fielding S, Mustard AT, Pollard RT, Popova EE, Smeed DA, Srokosz MA (2003) Along or across front survey strategy? An operational example at an unstable front. Geophys Res Lett 30(1):1017-1-1017-4

Rodriguez J, Tintore J, Allen JT, Blanco JM, Gomis D, Reul A, Ruiz J, Rodriguez V, Echevarria F, Jimenez-Gomez F (2001) Mesoscale vertical motion and the size structure of phytoplankton in the ocean. Nature 410:360-363

Rossby CG (1940) Planetary flow patterns in the atmosphere. Quart J Roy Met Soc 66(Suppl):68-87

Ruiz S, Pascual A, Garau B, Pujol I, Tintoré J (2009) Vertical motion in the upper ocean from glider and altimetry data. Geophys Res Lett 36:L14607. https://doi.org/10.1029/2009GL038569

Strass V and Woods JD (1988) Horizontal and seasonal variation of density and chlorophyll profiles between the Azores and Greenland. In: Rothschild B (ed) Towards a theory on biological- physical interactions in the world ocean, Kluwer, p 113-136

Thomas LN, Tandon A, Mahadevan A (2008) Sub-mesoscale processes and dynamics. In: Hecht MW, Hasumi H (eds) Ocean modeling in an eddying regime, geophysical monograph series, vol 177. American Geophysical Union, Washington DC, pp 17-38

Turner JT (2002) Zooplankton fecal pellets, marine snow and sinking phytoplankton blooms. Aquat Microb Ecol 27:57-102

Woods JD (1988) Mesoscale upwelling and primary production. In: Rothschild B (ed) Towards a theory on biological-physical interactions in the world ocean, Kluwer, p 7-38 